\title{
Correlation of pre-earthquake electromagnetic signals with laboratory and field rock experiments
}

\author{
T. Bleier ${ }^{1}$, C. Dunson ${ }^{1}$, C. Alvarez ${ }^{1}$, F. Freund ${ }^{2}$, and R. Dahlgren ${ }^{3}$ \\ ${ }^{1}$ Quakefinder, Palo Alto, Ca, USA \\ ${ }^{2}$ NASA Ames Research Center, Moffett Field, Ca, USA \\ ${ }^{3}$ Dept. of Physics and Astronomy, San José State University, San José, Ca, USA
}

Received: 10 May 2010 - Revised: 20 August 2010 - Accepted: 3 September 2010 - Published: 24 September 2010

\begin{abstract}
Analysis of the 2007 M5.4 Alum Rock earthquake near San José California showed that magnetic pulsations were present in large numbers and with significant amplitudes during the 2 week period leading up the event. These pulsations were $1-30 \mathrm{~s}$ in duration, had unusual polarities (many with only positive or only negative polarities versus both polarities), and were different than other pulsations observed over 2 years of data in that the pulse sequence was sustained over a 2 week period prior to the quake, and then disappeared shortly after the quake. A search for the underlying physics process that might explain these pulses was was undertaken, and one theory (Freund, 2002) demonstrated that charge carriers were released when various types of rocks were stressed in a laboratory environment. It was also significant that the observed charge carrier generation was transient, and resulted in pulsating current patterns. In an attempt to determine if this phenomenon occurred outside of the laboratory environment, the authors scaled up the physics experiment from a relatively small rock sample in a dry laboratory setting, to a large 7 metric tonne boulder comprised of Yosemite granite. This boulder was located in a natural, humid (above ground) setting at Bass Lake, Ca. The boulder was instrumented with two Zonge Engineering, Model ANT4 induction type magnetometers, two Trifield Air Ion Counters, a surface charge detector, a geophone, a Bruker Model EM27 Fourier Transform Infra Red (FTIR) spectrometer with Sterling cycle cooler, and various temperature sensors. The boulder was stressed over about $8 \mathrm{~h}$ using expanding concrete (Bustar ${ }^{\mathrm{tm}}$ ), until it fractured into three major pieces. The recorded data showed surface charge build up, magnetic pulsations, impulsive air conductivity changes, and acoustical cues starting about $5 \mathrm{~h}$ before the boulder actually
\end{abstract}

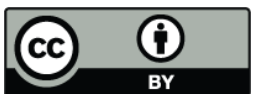

Correspondence to: T. Bleier (tbleier@quakefinder.com) broke. These magnetic and air conductivity pulse signatures resembled both the laboratory rock stressing results and the 30 October 2007 M5.4 Alum Rock earthquake field data.

The second part of this paper examined other California earthquakes, prior to the Alum Rock earthquake, to see if magnetic pulsations were also present prior to those events. A search for field examples of medium earthquakes was performed to identify earthquakes where functioning magnetometers were present within $20 \mathrm{~km}$, the expected detection range of the magnetometers. Two earthquakes identified in the search included the 12 August 1998 M5.1 San Juan Bautista (Hollister Ca.) earthquake and the 28 September 2004 M6.0 Parkfield Ca. earthquake. Both of these data sets were recorded using EMI Corp. Model BF4 induction magnetometers, installed in equipment owned and operated by UC Berkeley. Unfortunately, no air conductivity or IR data were available for these earthquake examples. This new analysis of old data used the raw time series data ( 40 samples per s), and examined the data for short duration pulsations that exceeded the normal background noise levels at each site, similar to the technique used at Alum Rock. Analysis of Hollister magnetometer, positioned $2 \mathrm{~km}$ from the epicenter, showed a significant increase in magnetic pulsations above quiescient threshold levels several weeks prior, and especially 2 days prior to the quake. The pattern of positive and negative pulsations observed at Hollister, were similar, but not identical to Alum Rock in that the pattern of pulsations were interspersed with Pc 1 pulsation trains, and did not start 2 weeks prior to the quake, but rather 2 days prior. The Parkfield data (magnetometer positioned $19 \mathrm{~km}$ from the epicenter) showed much smaller pre-earthquake pulsations, but the area had significantly higher conductivity (which attenuates the signals). More interesting was the fact that significant pulsations occurred between the aftershock sequences of quakes as the crustal stress patterns were migrating.

Published by Copernicus Publications on behalf of the European Geosciences Union. 
Comparing laboratory, field experiments with a boulder, and earthquake events, striking similarities were noted in magnetic pulsations and air conductivity changes, as well as IR signals (where instrumented). More earthquake samples, taken with the appropriate detectors and within $10-15 \mathrm{~km}$ proximity to large ( $>$ M5) earthquakes, are still needed to provide more evidence to understand the variability between earthquakes and various electromagnetic signals detected prior to large earthquakes.

\section{Introduction}

A number of papers have reported various electromagnetic signals being detected prior to large earthquakes. These include the M7.0 Loma Prieta, Ca. quake in 1989 (FraserSmith, 1990, 1991), Izu Islands earthquake swarm, Japan (Hattori, 2004), and the M5.4 Alum Rock, Ca. quake in 2007 (Bleier, 2009). In addition, work has evolved trying to explain the underlying physics involved with these electromagnetic signals. Two theories have been cited recently. The first is based on the release of Radon gas prior to the earthquake, which may then cause air conductivity changes, latent heat/IR signatures, and ionospheric changes (Liu, 2004; Ouzounov, 2007). The second theory is based on semiconductor physics, and cites the existence of stress-induced mobile charge carriers (p-holes) in the rock structure that cause active current pulses within rocks, corresponding magnetic pulsations, air conductivity changes near the ground, Infra Red (IR) signatures within a wider area, and Total Electron Content (TEC) changes in the ionosphere above the epicenter (Freund, 2006, 2007).

There were no radon detector data sets that could be found to try to correlate with California earthquakes.

The first objective of this paper was to devise an experiment that could test the semi-conductor theory under more "normal" outside conditions rather than temperature and humidity within controlled laboratory experiments. Based on the initial results from the laboratory experiments by Freund, we decided to "scale up" the experiment and determine if these same semiconductor effects could be detected with much larger samples, located in a natural setting, with natural humidity and temperature conditions of a field location. The authors had access to a large 7 metric tonne boulder, composed of Yosemite granite, at a construction site near Bass Lake, Ca. The authors collaborated to instrument the boulder with magnetometers, air conductivity and surface charge detectors, and a Sterling-cycle cooled IR spectrometer. The $2 \mathrm{~m}$ by $1.5 \mathrm{~m}$ by $1.5 \mathrm{~m}$ boulder was located on a hillside, in the open, and thus subject to local humidity and temperature variations throughout the day and night. This experiment will be described in sections $2-3$ of this paper. The infra red (IR) energy detected from the boulder while under stress will be addressed in future paper by Freund. This data was then compared against similar signals (magnetic pulses and IR) detected at the 30 October 2007 M5.4 Alum Rock earthquake event.

The second objective of this paper was to re-examine several archived earthquake events that were fortuitously located near magnetometers and had raw time series data over several years that could be examined for magnetic pulsations. Two earthquake data sets were identified, one for the $12 \mathrm{Au}-$ gust 1998 San Juan Bautista M5.1 earthquake near Hollister California (Berkeley SAO magnetometer data set for 19971998), and one for the 28 September 2004 Parkfield, Ca. M6.0 quake (Berkeley PKD magnetometer data set from 2003-2004). Section 4 of this paper describes this analysis.

The theory of charge carriers (Freund, 2006, 2007) would predict that both the boulder experiment and the 2 additional earthquake data sets should indicate magnetic pulsations recorded in the local magnetometer instruments, and the signatures (pulse shapes and polarities) should be similar. This above ground boulder was a first step in examining in situ rock responses to stress. In the future, an additional rock stressing experiment is being proposed for an area several thousand feet below the ground at the Deep Underground Science Experiment Laboratory (DUSEL), located at the former Homestake gold mine in Lead, North Dakota. There, the stress levels, heat, moisture, and boundary conditions may be even closer to actual earthquake hypocenter conditions.

\section{Boulder experiment}

In multiple laboratory rock stressing experiments (Freund, 2006), there was evidence of pulsating currents occurring as detected with nano-ammeters. Figure 1 illustrates the current signatures that were observed when granite was compressed.

Figure 2 shows a 7 metric tonne boulder, comprised of Yosemite granite, and located at $37.294301^{\circ} \mathrm{N}$ Latitude and $-119.520182^{\circ} \mathrm{W}$ Longitude near Bass Lake, Ca.

The boulder was prepared by drilling an array of four $5 \mathrm{~cm}$ diameter by $1.1 \mathrm{~m}$ blind holes pattern, along the centerline of the boulder, and subsequently left to dry and redistribute the stress over a 3 week quiet period. This is shown in Fig. 3.

The boulder was then instrumented using two Zonge Eng. Model ANT4 induction type magnetometers, two Trifield Air Ion Counters, a "capacitor-type" surface charge detector (approx. $30 \mathrm{~cm}$ square copper sheet and an interstitial mylar insulator sheet, a $4 \mathrm{~Hz}$ geophone, a Bruker Model EM27 IR spectrometer with Sterling-cycle cooler, and 3 temperature sensors (one mounted in the center hole, one mounted on the East face, and one mounted on the West face of the boulder). Figure 4 illustrates the approximate layout of the sensors.

During the boulder experiment, the Air Ion Detectors were set to a maximum of $1999 \times 10^{6}$ ions per cc per sec flow rate. One meter was set to negative polarity (and worked well), and the other was set to center position (which at the time we thought was "both" polarities, but actually did not register 


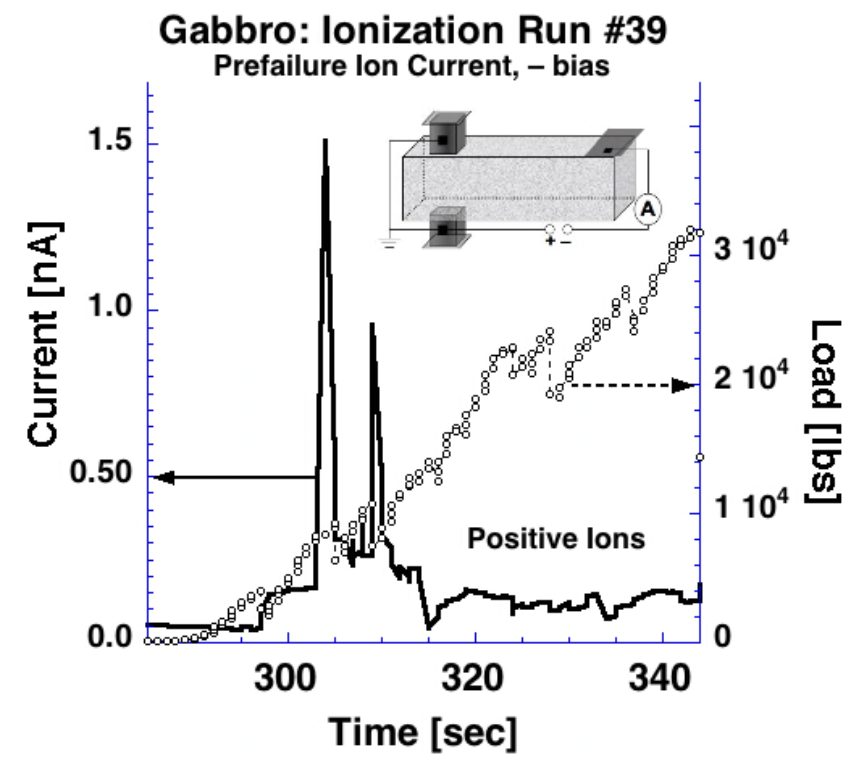

Fig. 1. Current profile of stressed Gabbro rock (Freund, 2006).

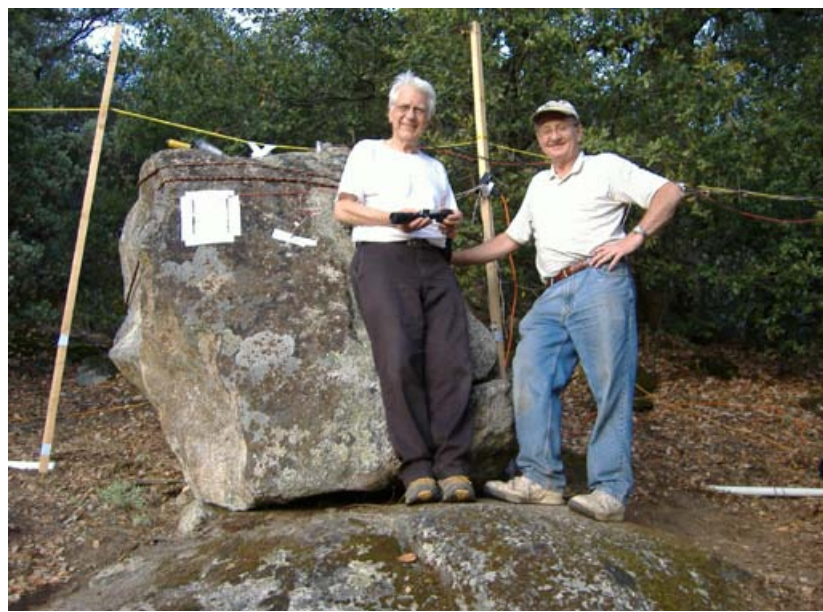

Fig. 2. Yosemite granite 7 metric tonne boulder, Freund (left) and Bleier (right).

either polarity). The two Trifield Air Ion detectors were located near the top of the boulder, suspended approximately $20 \mathrm{~cm}$ above the north and southern portion of the boulder. The magnetometers were located on the ground, in shallow trenches, approximately $1 \mathrm{~m}$ north and $1 \mathrm{~m}$ to the south of the boulder, with the axis of the magnetometer pointed toward the base of the boulder. Two temperature sensors were located on the East and West faces of the boulder respectively, while one sensor was lowered into a central bore hole, to a depth of approximately tcenter of the rock. Note this sensor functioned temporarily until the expanding concrete crushed the sensor, and from then forward, the center temperature data was unusable.

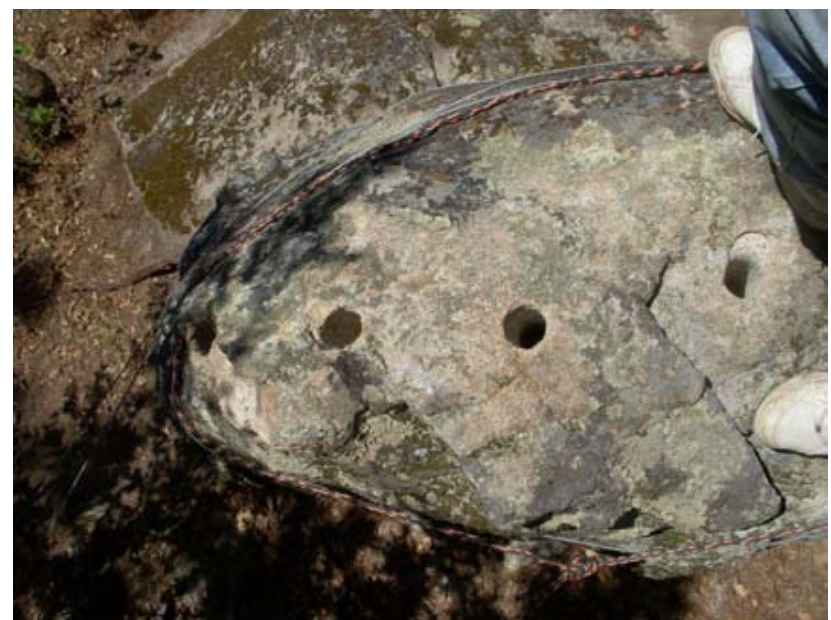

Fig. 3. Top view of the boulder illustrating the 4 vertical hole pattern before filling.

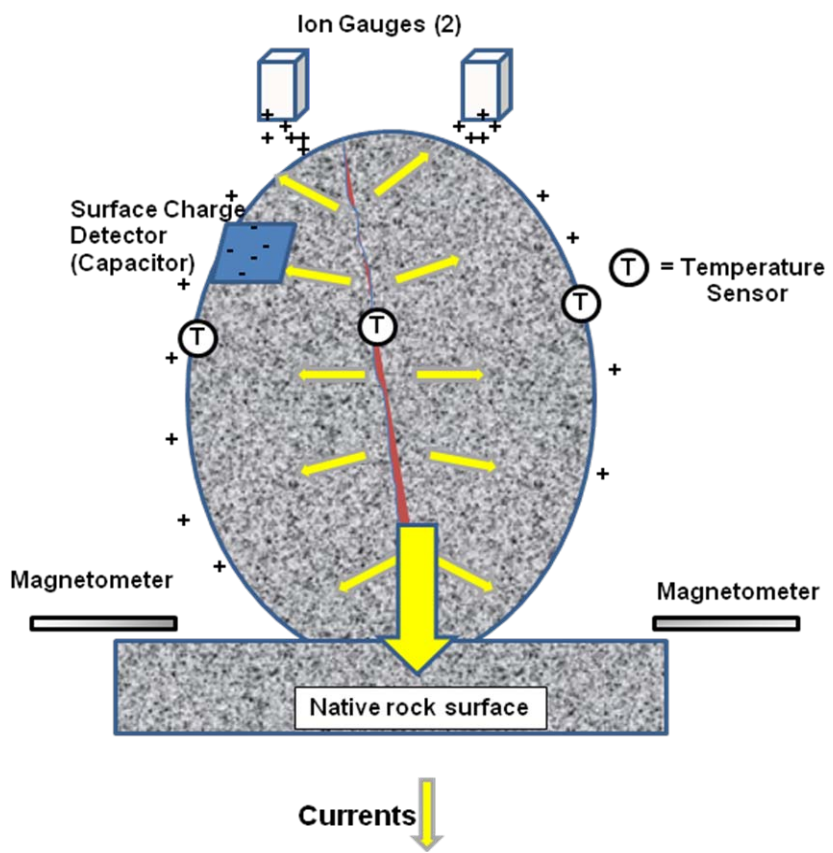

Fig. 4. A schematic view of the boulder and instrument layout, North is left, and South is right.

The expanding cement (Bustar ${ }^{\mathrm{TM}}$ ) was added at $10 \mathrm{p} . \mathrm{m}$. at night and allowed to cure, continuously expanding until the boulder fractured around 05:30 a.m. the following morning as shown in Figs. 5 and 6.

The boulder started to become electrically active around $2 \mathrm{~h}$ into the test at approximately midnight, and simultaneously, the magnetometer, air conductivity, surface charge sensor, and geophone all showed active signals.

Figure 6 shows the various signatures around midnight. A negative power supply failed around $2 \mathrm{a} . \mathrm{m}$. affecting the operational amplifier circuits, but the main signals were 


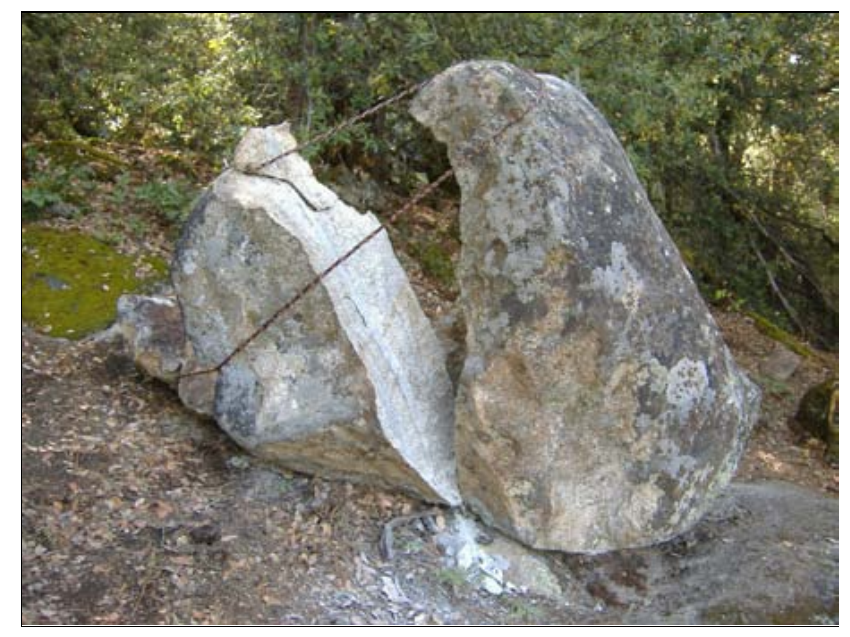

Fig. 5. The boulder shown split into 3 major pieces along the plane defined by the hole pattern.

recorded before that time. The activity on the magnetometer channels at the times of the instrument setup and the pouring of the expanding cement were due to the team walking past the magnetometers with cellphones and metal tools. Once the team vacated the area, the magnetometer signals reverted to the normal background signals. Unusual signals started just before the midnight calibration signal, and went quiet afterward until the magnetometer channels became inoperative when the power supply failed at 2 a.m.

Figure 7 shows the magnetic pulses and their durations. The sinusoidal wave on the right of the time span is the start of the $5 \mathrm{~min}$ long, $0.8 \mathrm{~Hz}$ calibration signal sent to the magnetometers every midnight. The 3 pulses (widths) are longer than lightning, typically 0.1 to $0.5 \mathrm{~s}$, and coincident with the other EM signals detected when the boulder started to mechanically fail.

Figure 8 illustrates the geophone vibrations, also detected near midnight. The magnetometer calibration sine wave packet is also detected as crosstalk in the geophone signal wiring, but also serves as a time reference. There appears to be two mechanical/vibration events for each magnetic pulse.

Figure 9 illustrates the positive and negative ion pulsations detected, near midnight.

These large concentrations of ions are unusual in that there are periods of predominately positive ions and other periods of predominantly negative ions. The pulse periods are short, and the pulsations stopped around $4 \mathrm{~min}$ after midnight.

Figure 10 below shows the surface charges detected with an improvised "capacitor" type charge detector and a voltmeter during the stressing period. Until midnight, the charge concentration appears to be positive. Then at midnight, something changes and the net charge changes to negative until the boulder ruptures at 05:30 PST (06:30 PDT).

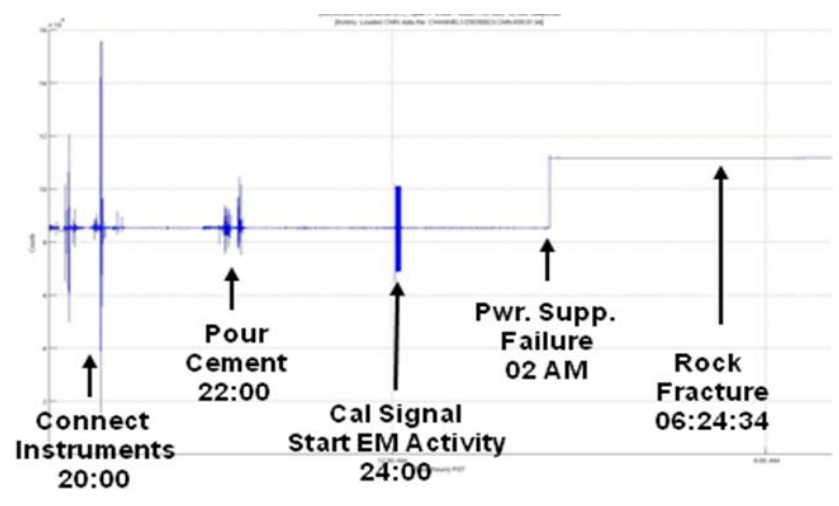

Fig. 6. Experiment timeline on 20-21 August 2009.

\section{Comparison of rock experiments with Alum Rock earthquake field data}

\subsection{Comparison of magnetic pulses}

Figure 11 illustrates the types of pulses observed during the boulder experiment (bottom panel), and sample prior to the 2007 Alum Rock M5.4 earthquake (top panel). The bottom panel represents a single pulsation, while the Alum Rock signature is a series of single pulsations, merging into a strong cluster that persists for almost $150 \mathrm{~s}$. Many of the individual pulses in Alum Rock data are similar in duration to the single pulse in the boulder example.

An inspection of the data was used to set a minimum threshold for detecting and counting these pulsations in order to not count normal background noise.

A pulse duration threshold was set to ignore all pulses shorter than $1 \mathrm{~s}$. to eliminate power line switching noise and occasional lightning strikes (those that could be detected closer than $150 \mathrm{~km}$ ). The next pulse threshold was an amplitude level threshold that was selected to eliminate vehicular and other man-made noise in the local area. Using such an amplitude threshold (red dotted lines) representing twice (2x) the peak local man-made noise measured at that site location, any pulses larger than the threshold were counted each day and stored. Coordination with the site's landowner, inspection of the pulse activity, and correlation with the colocated geophone instrument allowed the man-made noise to be identified (e.g. construction activity and farm implement movements.) When the known human noise periods were identified, the contaminated noise periods were masked from the pulse files so the long term pulse activity would not be contaminated. Figure 12 illustrates this process, and also shows the nature of some of the non-man made pulse activity. "BART" in Fig. 12 refers to Bay Area Rapid Transit trains that generate ULF noise which can contaminate the signal. 


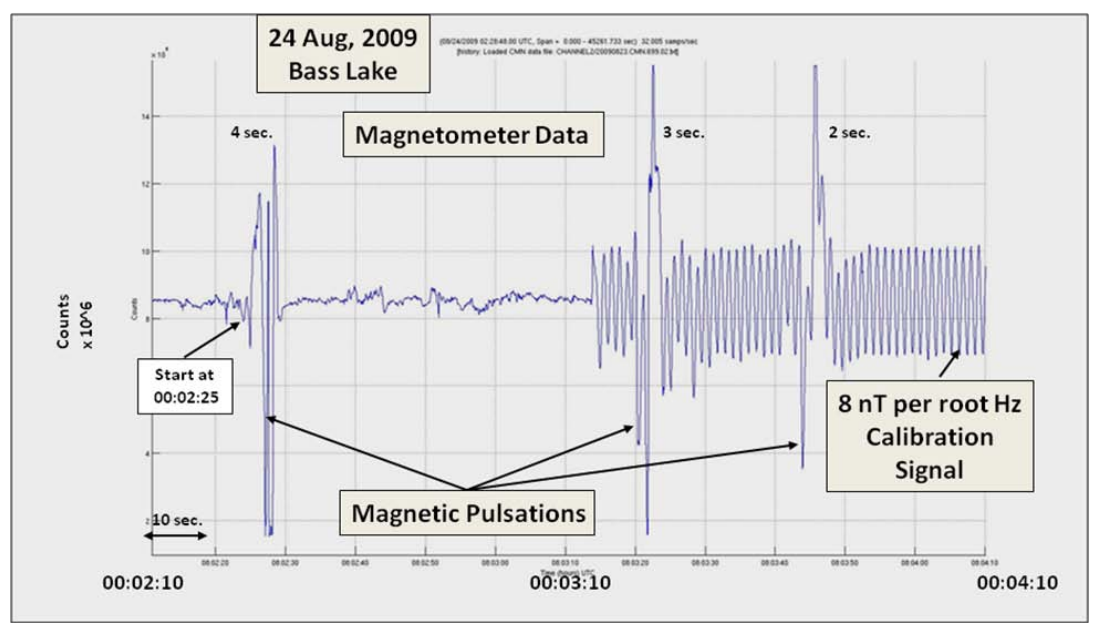

Fig. 7. Magnetic pulsations detected near midnight.

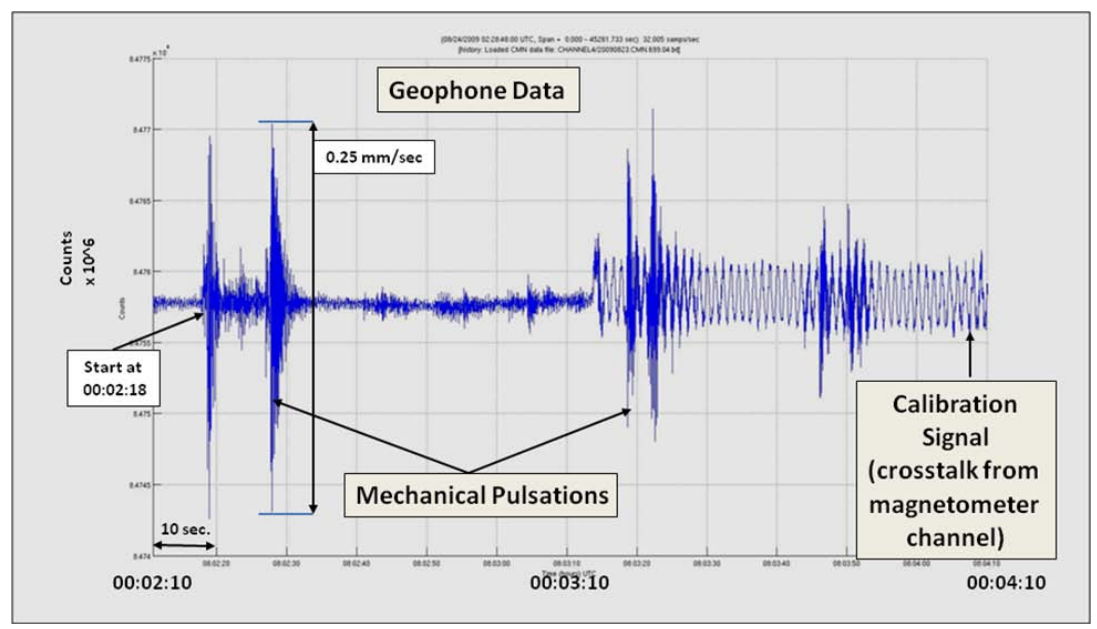

Fig. 8. Output of the geophone, embedded near the south face of the boulder.

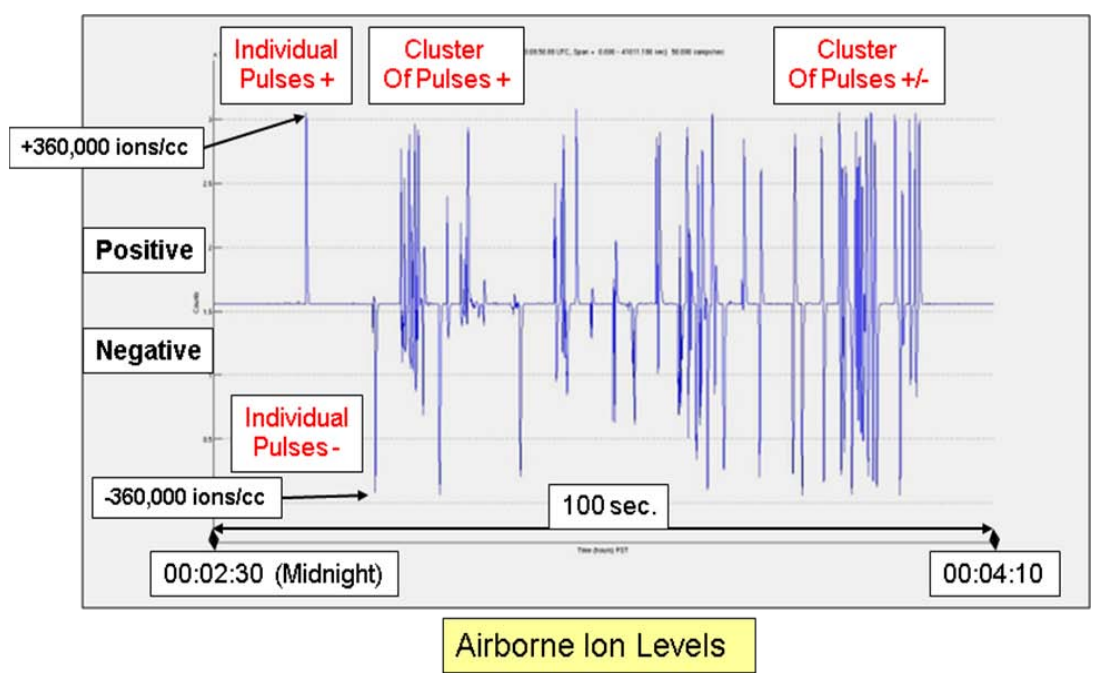

Fig. 9. The simultaneous (midnight) surge of positive and negative ion concentrations in the air $20 \mathrm{~cm}$ above the boulder. 


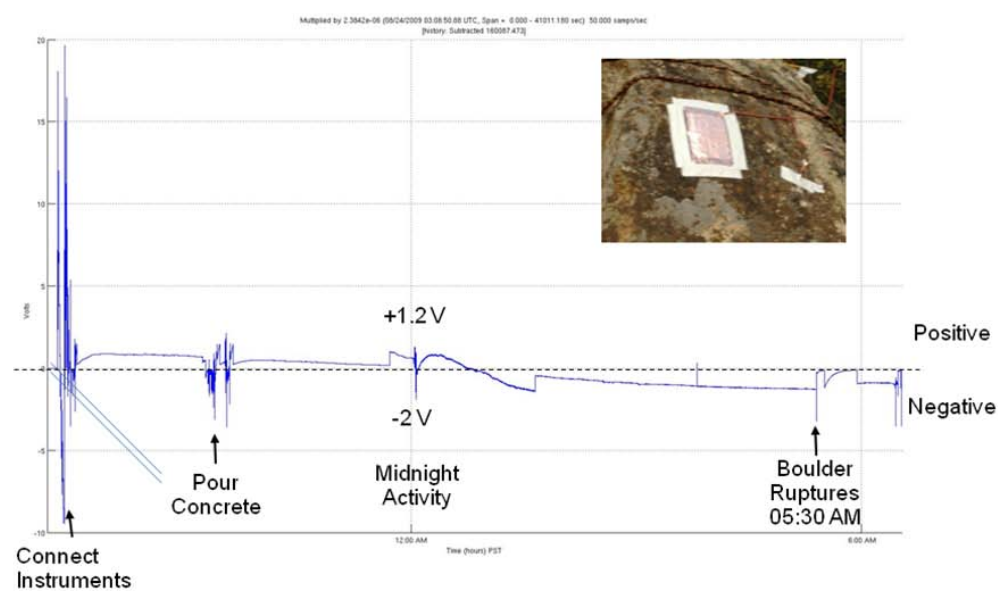

Fig. 10. Surface charge variations throughout the boulder stressing experiment.

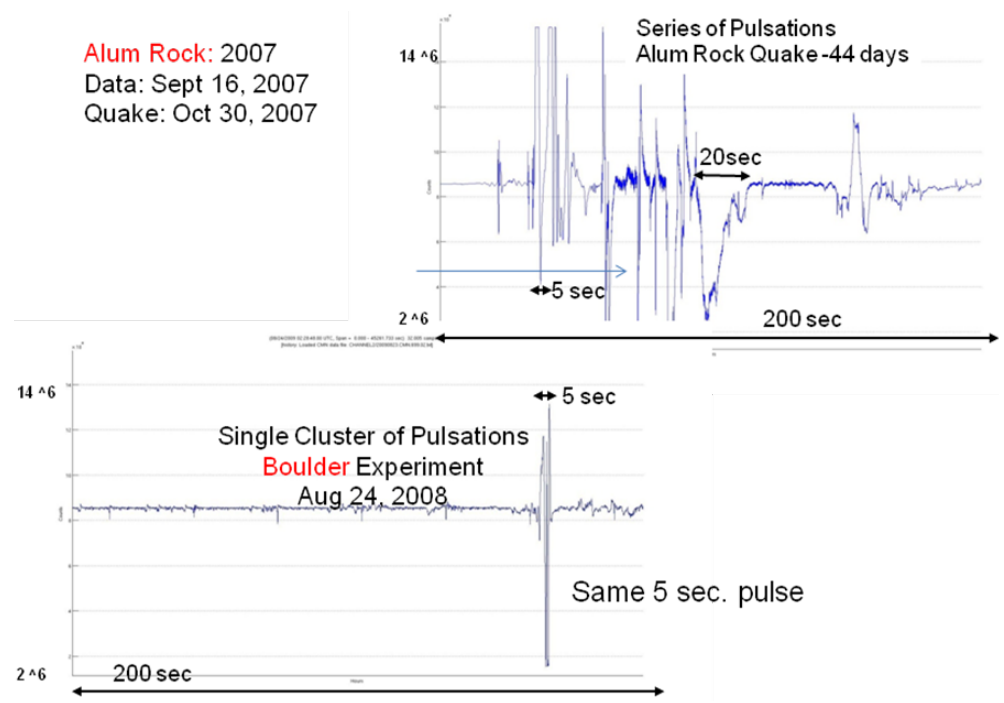

Fig. 11. Alum Rock magnetic pulsations (top) and boulder magnetic pulsations (bottom).

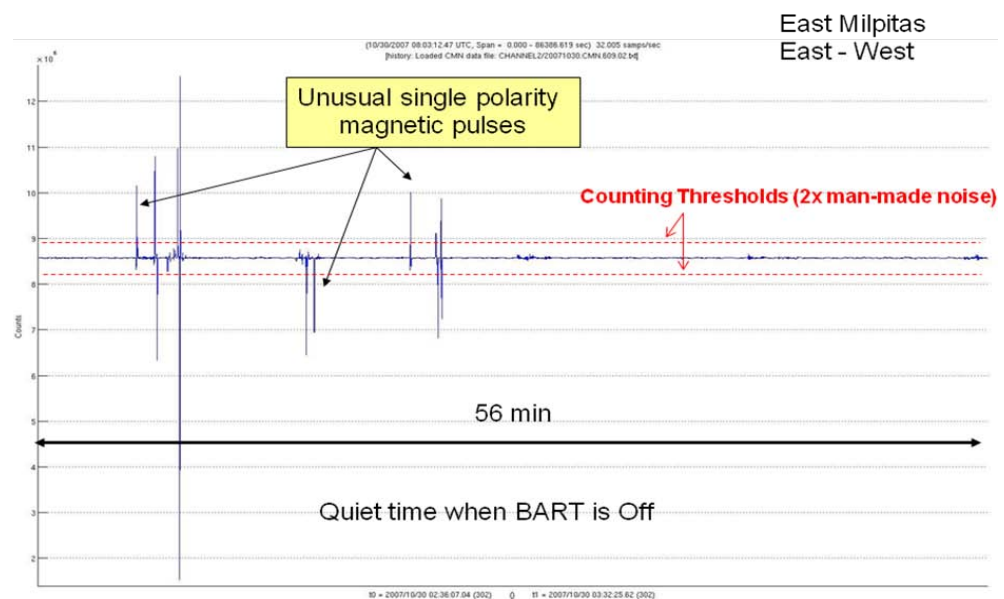

Fig. 12. Threshold amplitude limits, with positive and negative pulse examples. 


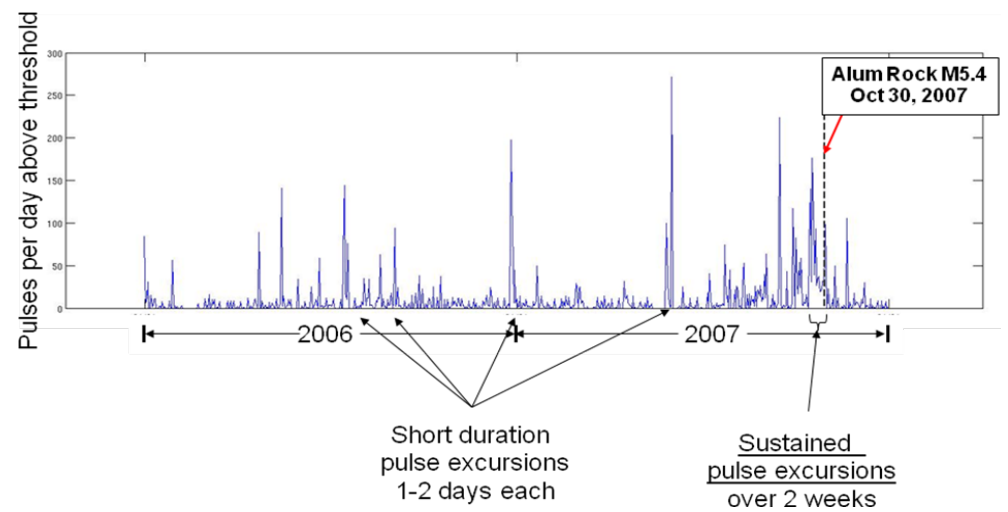

Fig. 13. Two year pulse count activity for East Milpitas.

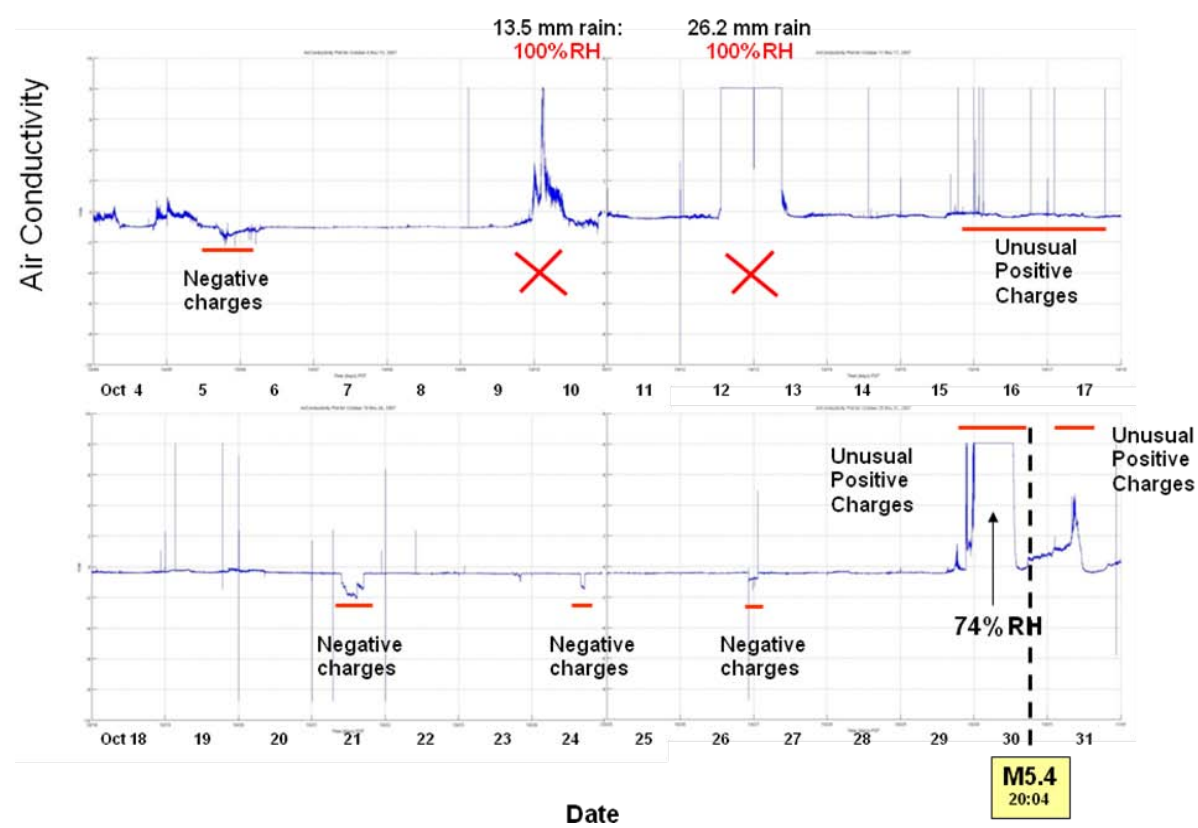

Fig. 14. Alum Rock ionization history for October 2007.

The result of counting these pulses at East Milpitas $(2 \mathrm{~km}$ from the earthquake) is shown in Fig. 13: the pulse history shows that the fault had multiple periods of activity (high pulse counts), but that most of the periods were short (13 days). The discriminator prior to the quake was that the pulse activity continued for almost 14 days before the fault activity "avalanched" into an earthquake event.

\subsection{Comparison of air conductivity}

The air conductivity in the lab was difficult to measure due to the small sample size and shielding components. There were IR emissions, so it is plausible that there was air ionization.

Taking measurements near the boulder in the field was straight forward. Two digital Air Ion detectors were installed near the sample. The negative ion meter's data is shown in Fig. 9.
Figure 14 Air Ion particle concentrations measured from $20 \mathrm{~cm}$ above the boulder.

During the boulder experiment, the weather was warm and dry with no thunderstorm activity within hundreds of kilometers of the test site. Weather conditions from 20:00 PDT 20 August to $05: 3021$ August were $20.3{ }^{\circ} \mathrm{C}$ to $16.0^{\circ} \mathrm{C}$ with the barometric pressure at $757 \mathrm{~mm} \mathrm{Hg}\left(28.9^{\prime \prime} \mathrm{Hg}\right)$ and slowly rising. There were no fog, clouds, or thunderstorm activity present that could contaminate the test. The air ion activity was negligable before and immediately after the instrument setup and into the stressing period. When ion signals suddenly started occuring near midnight, the ion signatures could not be explained by any local activity (natural or human) other than the rock stressing activity. 


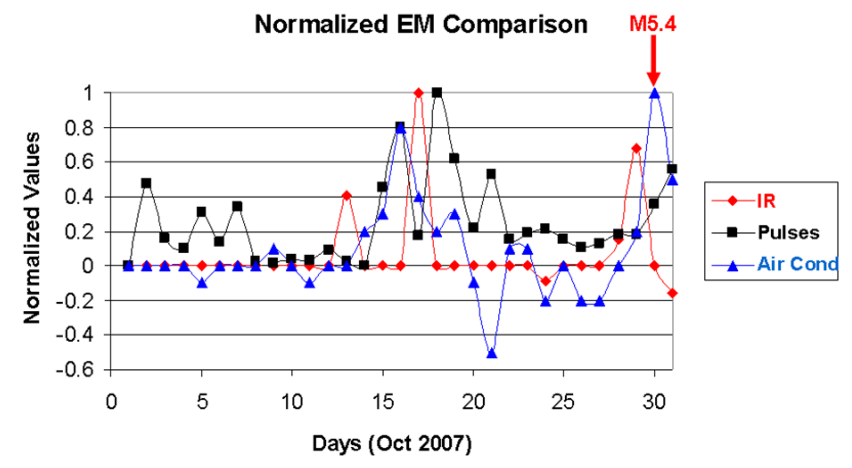

Fig. 15. Comparison of 3 independent electromagnetic indicators prior to the Alum Rock earthquake.

Next, we compared this test with an actual earthquake data set. The Alum Rock field ionization data for a one month period prior to the earthquake is shown in Fig. 14 above. The spacing of the pulses in Fig. 14 on the right side start to get close together, and on a larger time scale, could be seen to appear as a single saturated signal.

Figure 14 shows both individual conductivity pulsations (sharp spikes) as well as periods of totally saturated readings. The red " $X$ " delineates contaminated data due to rain (high humidity) causing vapor condensation on the sensor plates and resulting in false signal current.

All these EM indicators (magnetic pulses and air conductivity, as well as IR observed over earthquake areas, namely, the night time IR temperature slope as detected by the GOES weather satellite using its IR camera) are influenced by noise in the data (e.g. noise such as lightning in magnetic data, high humidity in air conductivity data, and clouds in the IR data). One way to reduce the effect of individual noise contributors is to observe all three EM indicators over the same area and time to see if they occur simultaneously.

Figure 15 illustrates the combined pattern of the pulses, IR and air conductivity, normalized to their highest readings (where the ratio $=1.0$ for the highest reading for that indicator).

In Figure 15, we sought to determine if there were correlations among 3 indicators: magnetic pulse counts, air conductivity, and Infra Red. The fact that they all appeared to peak at the same times (14 days prior to the quake and the day just prior to the quake, is interesting and may allude to some combined effect from the existence of the charged particles generated in the sub-surface area near the earthquake. Other indicators could be added to increase the robustness and confidence levels of this correlation search, e.g. earthquake swarms, earthquake lights, ionospheric (TEC) changes above the epicenter area, cloud patterns, underground water level changes, chemical or gas changes, etc.

\section{Search for other earthquake field magnetometer data comparisons}

The 30 October 2007, M5.4 Alum Rock earthquake data represents a single case where detailed analysis of the time series and pulsation history of a site exists for a 2 year period. In the case of the 17 October 1989, M7.0 Loma Prieta earthquake, Fraser-Smith was not able to store the raw time series magnetometer data, and therefore individual pulses could not be identified and counted using the QuakeFinder pulse counting method. However, California had two other cases of full time series recordings of magnetometer data: the 12 August 1998, M5.1 San Juan Bautista earthquake at Hollister Ca. where the data from the SAO site was recorded by the Seismo-Lab at UC Berkeley, and the 28 September 2004, M6.0 Parkfield earthquake where the magnetometer data was recorded by the PKD site, also by the Seismo-Lab at UC Berkeley. Previous papers from Stanford and USGS reported no significant magnetometer signals were present at these sites prior to the earthquakes. The Parkfield $M 6$ analysis showed no significant magnetic field changes (Johnston, 2008), but the magnetometers utilized were total field magnetometers (Proton Precession) with slower sampling rates. The San Juan Bautista analysis (Karakelian, 2002) reported only minor signals, but the data collection method again used $30 \mathrm{~min}$ averages or $1 \mathrm{~min}$ averages ( $1 \mathrm{~min}$ averages actually showed some interesting signal increases in the Karakelian paper). The use of 1 to 30 min energy averages is a good technique if the signals are continuous. However, when the signals are infrequent $1-10 \mathrm{~s}$ pulsations, this method tends to "average out" the signal amplitudes over the 60-1800 s sample periods.

In our analysis, we obtained a two year raw data record of each of these sites before their respective earthquakes and performed the same pulse analyses as the Alum Rock event. Background noise was identified by observation, and threshold limits were set at $2 \mathrm{X}$ these noise readings.

The raw time series for Hollister site is shown in Fig. 16 for selected days around the 1998 earthquake.

In the Hollister data, episodes where there were man-made noise segments (e.g. the site was down for maintenance and people were walking around the site) were identified and excluded from the pulse counting data base. Large solar storms $(\mathrm{Kp}>7)$ were identified and the resulting noisy segments were also excluded. These segments are identified in the list shown at the left side of Fig. 17.

Similar episodes of pulse activity to the Alum Rock case can be seen, with the largest being 2 days prior to the Hollister quake.

10 August (2 days prior to the quake) showed a large pulse count (count $=801$ ). A more detailed examination of the time series showed many short pulses $(<1 \mathrm{~s})$ in the waveform, interspersed with a large, varying sine wave that appears to be a Pc 1 micropulsation train. The Kp values were $<3.8$ for the 2 days prior, so we did not expect to see any Pc 1 activity during that time. However, a similar large Pc 1 train 

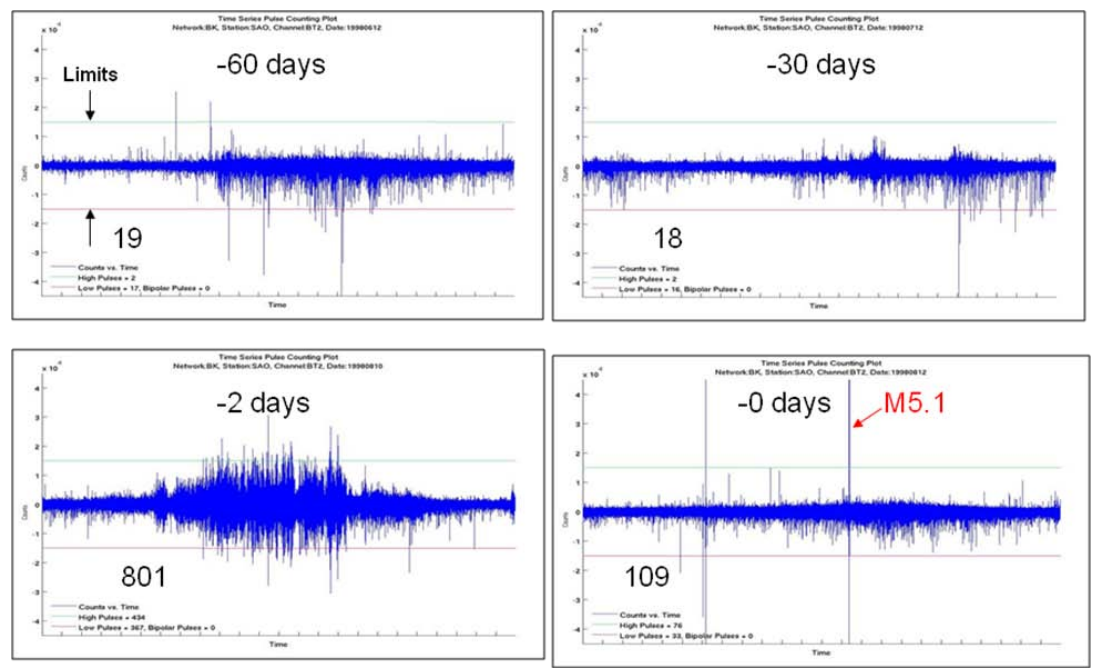

Fig. 16. Magnetic time series ( $24 \mathrm{~h}$ each panel) taken at various time prior to the M5.1 event.

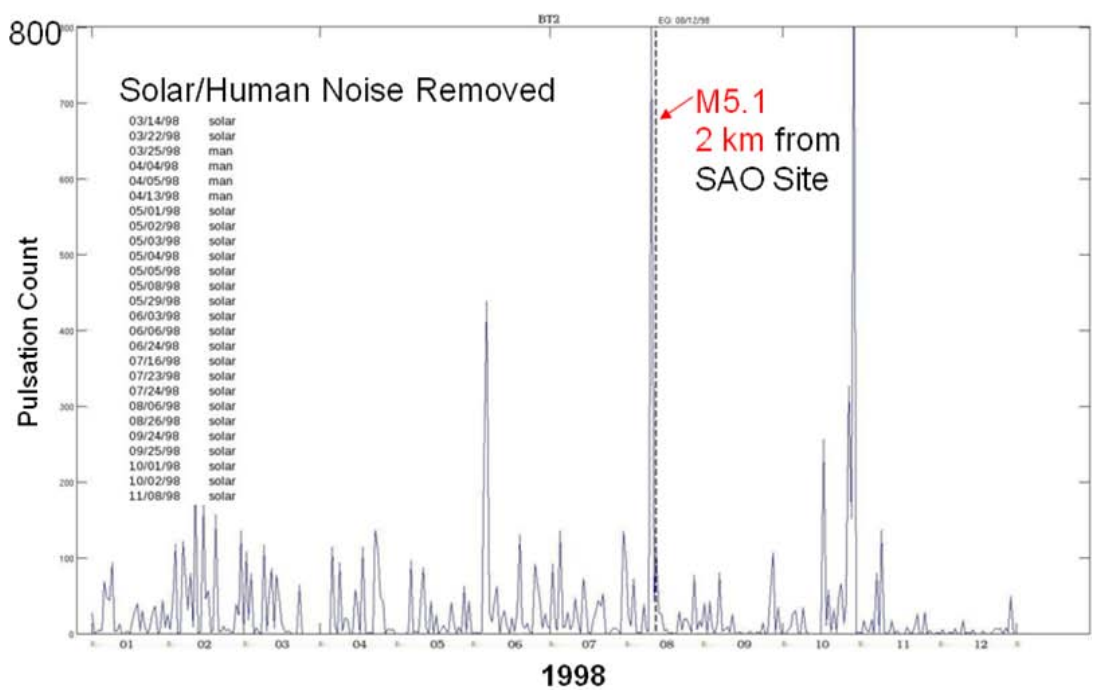

Fig. 17. One year plot of pulse activity recorded at Site SAO, $2 \mathrm{~km}$ from the earthquake epicenter.

occurred prior to the Parkfield quake, also during a quiet solar period. We do not have an explanation for this, but it appears that normal geomagnetic activity (e.g. faint Pc 1 activity during low Kp periods) is somehow amplified prior to both earthquakes. One theory is that the ionosphere is thinning out (negative particles are drawn closer to earth), and the ionospheric waveguide is changing such that a faint Pc 1 can "leak" down to the ground area and be detected easier by the ground-based magnetometers.

Our counting technique now does not distinguish between the individual pulses (as in Alum Rock), and the longer Pc 1 pulse trains as long as they are larger in magnitude than the upper or lower pulse height threshold. Therefore, the Hollister pulse counts are a combination of individual pulses and high amplitude periods of Pc 1-like pulse trains. A future paper will address the technique being developed to remove these Pc 1 micropulsations and constrain the pulse detector algorithm to count single pulses and ignore Pc 1 sinusoidal trains even during these periods of minor solar activity.

Another difference between Alum Rock and Hollister (San Juan Bautista) quakes is that a longer sustained pulse sequence (e.g. 14 days) did not occur as in the Alum Rock case. Hollister area is known as a highly broken area where the San Andreas joins with the Calaveras faults, and subsequently, there are typically many smaller earthquakes where the fault ruptures more often, and does not frequently build up to a large $(M 6+)$ stress levels. Finally, the large spike at the end of October (month 10) was not followed by any quakes larger than $M 3$, and could therefore be considered a "false positive" compared to the quake signature on $12 \mathrm{Au}$ gust 1998. In conclusion, Hollister could be considered to be a "marginal case" for pulse counting success. 

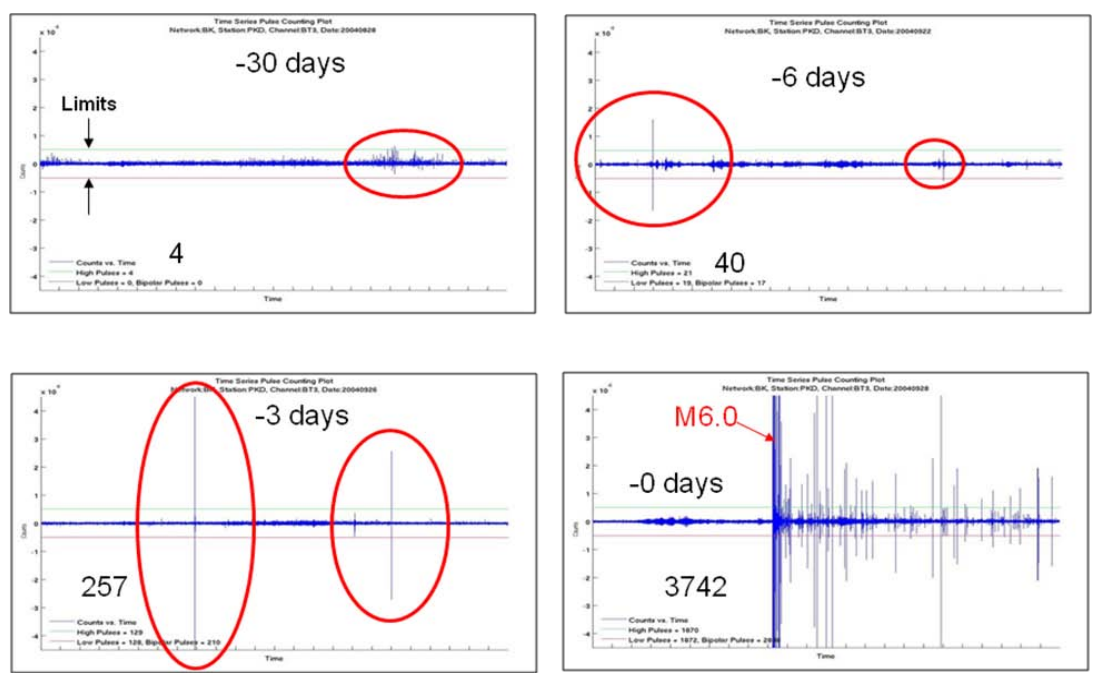

Fig. 18. Four single day periods ( $24 \mathrm{~h}$ each) prior to the 30 October 2004 M6.0 Parkfield earthquake.

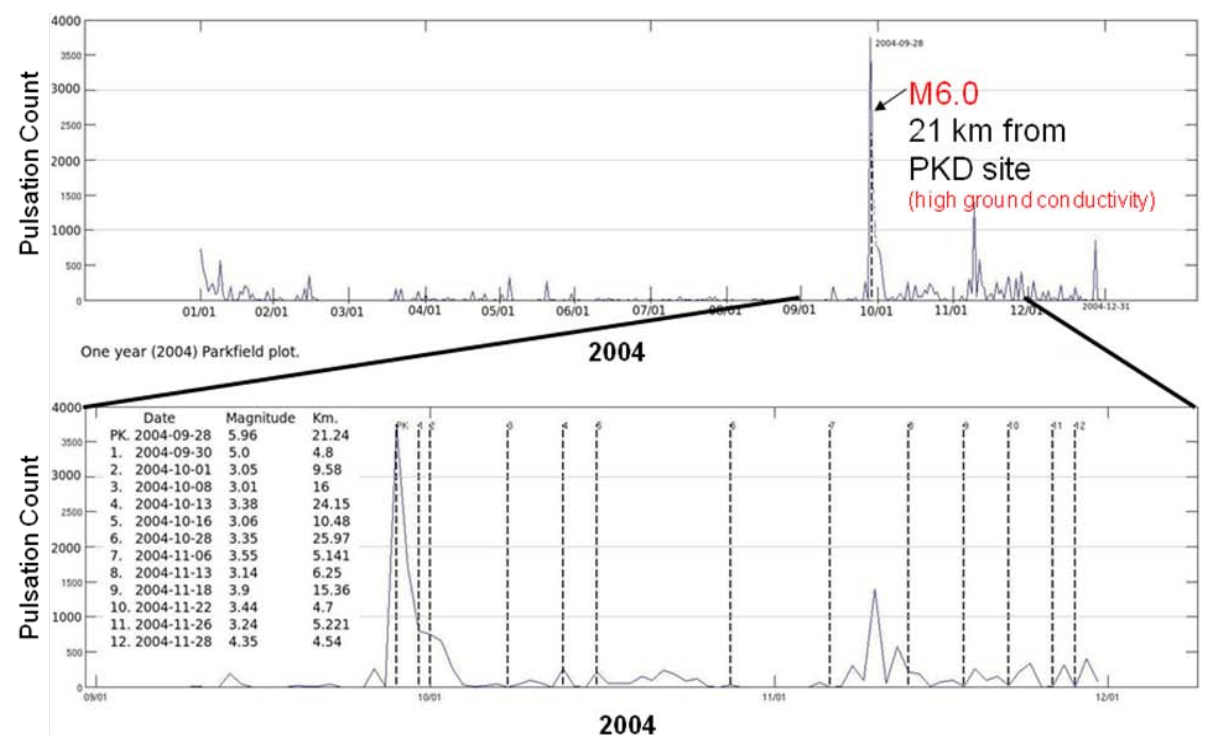

Fig. 19. One year history of pulse counts for Parkfield (top), and expanded time scale (3 months) bottom.

A second earthquake on 30 October 2004 at Parkfield shown in Fig. 18 was also reviewed, and shows a slightly different pattern.

Much smaller pulse patterns occurred (red circled areas), and the total pulse counts were also smaller until the day of the earthquake. Figure 19 below shows the pulse count history for the year leading up to the quake.

The table at the left of the bottom panel shows the aftershock activity including magnitude and distance from the epicenter. It is interesting to note the pulse activity is relative quiet prior to the quake, but is considerably more active $b e$ tween the aftershocks when the stress is being re-distributed to the surrounding area. A combination of the larger distance $(19 \mathrm{~km})$ between the epicenter and magnetometer instrument, and the high conductivity of the area all contributed to attenuation of the signals. A new paper (Bortnik, 2010) investigated the effect of conductivity on ULF wave propagation, and confirms this attenuation effect when conductivity is high.

\section{Noise and discriminators in the data}

All these data sets have noise. Magnetic pulsations must be screened for lightning and man-made activities. IR data must be filtered for clouds so that night time cooling can be calculated accurately. Air conductivity must be screened for periods of high relative humidity/rain when the sensor is contaminated by condensation moisture. Adding relative humidity 
and geophone instruments to each site for these noise sources and identifying their respective signal "footprints" is important to avoid "false positives".

Other electromagnetic "discriminators" may include specific wavelengths for IR data where the spectral peaks (and troughs) observed in the rock experiments may provide better signal-to-noise to detect the pre-earthquake IR signals. Determining the specific narrow bands, and taking the ratio of the high-to-low bands, has yet to be done.

Total Electron Content (TEC) variations at altitude above the earthquake zone may be another discriminator, but past reports have shown that the area of TEC disturbance can be as large as a continent, so spatial discrimination may be a challenge using TEC.

\section{Summary and conclusions}

Transient magnetic pulsations, observed in both laboratory rock experiments and in field boulder experiments, were also observed in 3 separate earthquake events (Alum Rock, Hollister, and Parkfield). The overall event samples are still small, but the pattern of pulsations appear to have some correlation to the size of the earthquake (Alum Rock M5.4 at 14 days prior, Hollister M5.1 at 2 days prior, and Parkfield $M 6$ is unclear due to the larger distance between the epicenter and the instrument.) Another mitigating factor was the previously discovered high conductivity of the Parkfield area to the east of the fault (Unsworth, 1999), which possibly attenuated the signals.

The correlation of magnetic pulsations, air conductivity, and anomalous Infra Red, may be a more powerful indicator when they appear in a pre-earthquake sequence similar to the Alum Rock earthquake, namely, pulsations and IR first, and sustained air conductivity levels seen closer to the actual event.

It should be noted that statistically, these interesting patterns still represent a very small sample size, and many more quakes need to be examined. However, it does highlight the importance of having calibrated instruments near (e.g. less than $30 \mathrm{~km}$ ) from the epicenter of future medium to large earthquake ( $>$ M5) so that the data can be obtained, compared, analyzed, and cross-correlated to other earthquake examples. QuakeFinder is attempting to maintain the current CalMagNet, and to develop a lower cost instrument, with induction magnetometers and calibrated air ion detectors to detect these EM signals. The new sensors will continue to employ relative humidity sensors and geophones to identify various contaminating signal sources.

Acknowledgements. The authors wish to acknowledge funding for this activity from C. Ford (Stellar Solutions), and J. LaBrecque (NASA Headquarters, Earth Surface and Interior Focus Area). We are also grateful for the supporting ULF data for PKD (Parkfield) and SAO (Hollister) from the UC Berkeley Seismo-Lab, and the solar $(\mathrm{Kp})$ and humidity data from NOAA.
Edited by: M. E. Contadakis

Reviewed by: I.-A. Moldovan and K. Eftaxias

\section{References}

Bleier, T., Dunson, C., Maniscalco, M., Bryant, N., Bambery, R., and Freund, F.: Investigation of ULF magnetic pulsations, air conductivity changes, and infra red signatures associated with the 30 October Alum Rock M5.4 earthquake, Nat. Hazards Earth Syst. Sci., 9, 585-603, doi:10.5194/nhess-9-585-2009, 2009.

Bortnik, J., Bleier, T. E., Dunson, C., and Freund, F.: Estimating the seismotelluric current required for observable electromagnetic ground signals, Ann. Geophys., 28, 1615-1624, doi:10.5194/angeo-28-1615-2010, 2010.

Freund, F.: Charge generation and propagation in rocks, J. Geodynamics, 33, 545-572, 2002.

Karakelian, D., Klemperera, S. L., Fraser-Smitha, A. C., and Thompson, G. A.: Ultra-low frequency electromagnetic measurements associated with the $1998 M_{\mathrm{W}} 5.1$ San Juan Bautista, California earthquake and implications for mechanisms of electromagnetic earthquake precursors, Tectonophysics, 359, 65-79, 2002.

Johnston, M. J. S., Sasai, Y., Egbert, G. D., and Mueller, R. J.: Seismomagnetic Effects from the Long-Awaited 28 September 2004 M6.0 Parkfield Earthquake, B. Seismol. Soc. Am., 98(4), 2087-2089, 2008.

Fraser-Smith, A. C., Bernardi, A., McGill, P. R., Ladd, M. E., Helliwell, R. A., and Villard Jr., O. G.: Low-Frequency Magnetic Field Measurements near the Epicenter of the Ms 7.1 Loma Prieta Earthquake, Geophys. Res. Lett., 17(9), 1465-1468, 1990.

Fraser-Smith, A. C., Bernadi, A., McGill, P. R., and Villard Jr., O. G.: ULF magnetic field measurements near the epicenter of the Ms 7.1 Loma Prieta Earthquake, Phys. Earth Planet. In., 68, 4563, 1991

Hattori, K.: ULF Geomagnetic anomaly associated with 2000 Izu Islands earthquake swarm, Japan, Physics and Chemistry of the Earth, Parts A/B/C, 29(4-9), 425-435, 2004.

Liu, J. Y., Chen, Y. I., Chuo, Y. J., and Tsai, H. F.: Variations of ionospheric total electron content during the Chi-Chi earthquake, Geophys. Res. Lett., 28, 1383-1386, 2001.

Ouzounov, D., Liu, D., Kang, C., et al.: Outgoing Long Wave RadiationVariability from IR Satellite Data Prior to Major Earthquakes, Tectonophysics, 431, 211-220, 2007.

Freund, F. T., Takeuchi, A., and Lau, B. W.: Electric currents streaming out of stressed igneous rocks - A step towards understanding pre-earthquake low frequency EM emissions, Phys. Chem. Earth, 31, 389-396, 2006.

Freund, F. T.: Stimulated IR emission from rocks: Assessing a stress indicator, eEarth, 2, 1-10, 2007.

Unsworth, M., Egbert, G., and Booker, J.: High-resolution electromagnetic imaging of the San Andreas fault in Central California, J. Geophys. Res., 104(B1), 1131-1150, 1999. 